\title{
POTENTIAL TOXICITY EVALUATION FOR A NANO-MODIFIED VENEERING CERAMIC SYSTEM. EXPERIMENTAL STUDY IN DOGS
}

\author{
Radwa M. El-dessouky* and Khaled M. Ali**
}

\begin{abstract}
Statement of problem: Although feldspathic porcelain is esthetic and biocompatible, it's considered a weak point in zirconia restorations. Researches are necessary to improve its flexural strength without affecting biological properties.

Purpose: to evaluate the possible toxic effects of incorporating $\mathrm{ZrO}_{2}$ Nanoparticles into conventional veneering ceramic system.

Materials and Methods: Four veneering ceramic systems [Ex0, Ex5, Ex10\&Ex20] were formulated by incorporating zirconia NPs into feldspathic powder [0\%, 5\%,10\% \& 20\% wt.] respectively. Twenty dogs were grouped into 4 groups to receive the 4 experimental ceramic systems. The 3rd mandibular premolar for each dog was prepared for zirconia crowns. Impressions were taken for production of zirconia copings, veneered with experimental ceramics \& delivered. After $3 \& 6$ months gingival specimens were collected\& subjected to Real-time PCR test to assess genotoxicity of the 4 experimental veneering ceramics.
\end{abstract}

Results: No genotoxicity was recorded for all groups in both $3 \& 6$ months. However, appoptic genes recorded in Ex0: $0.64 \pm 0.01 \& 0.65 \pm 0.02$, Ex5: 0.67 $\pm 0.02 \&$ 0.67 \pm 0.01 , Ex10:0.72 \pm 0.01 $\& 0.73 \pm 0.02$ and in Ex20: $0.88 \pm 0.01 \& 0.89 \pm 0.01$ compared to control (housekeeping gene) $0.96 \pm$ $0.01 \& 0.99 \pm 0.01$ for $3 \& 6$ months respectively. From clinical perspective; No local biological reactions were recorded.

Conclusion: No genotoxic effect was recorded in all groups. whereas, appoptic genes expressed higher level in proportional to NPs ratio. Generally, a satisfactory soft tissue response was observed.

* Assistant Lecturer, Fixed Prosthodontics Dept., School of Dentistry, Tanta University.

** Lecturer of Surgery and Anaesthesiology, Faculty of Veterinary Medicine, Cairo University 


\section{INTRODUCTION}

Zirconia-based ceramics have attracted the attention of researchers because of their excellent esthetics, superior flexural strength and biocompatibility ${ }^{1}$. On contrary, most veneering ceramics have low flexural strength; putting their strengthening as important research point to reduce fracture incidence of zirconia-based restorations ${ }^{2}$.

Evolution of Nanotechnology was a promising solution to produce a novel veneering ceramic system ${ }^{3}$.It is generally assumed that flexural strength of Nano-ceramics is higher than conventional ones. Moreover, the "in situ Nano-toughening" effect exerted by nano fillers within amorphous ceramic matrix can provide an extra crack bridging and deflection mechanisms ${ }^{4}$. Additionally, ceramics containing fine metastable zirconia grains $\left[\mathrm{ZrO}_{2}\right]$, have a superior benefit of transformation toughness ${ }^{5}$. Hence; yttria stabilized Zirconia Nanoparticles was the first candidate as a reinforcing agent for veneering ceramics.

Oral environment demands certain biological standards for dental restorative materials because of its confidentiality; Saliva is loaded with bacteria \& possesses corrosive properties. Moreover, immune system behaves differently in oral epithelium \&connective tissue rather than in the rest of body and hence, the Nano modified veneering ceramic intended to be used intra-orally should have strict pre-requisites ; First: harmless to local oral tissues and contain no toxic leachable agents which may be absorbed into circulatory system. Second: It should be free of allergic agents. Third: It should neither contain genotoxic nor mutagenic agents that alter the base pair sequence of DNA resulting in apoptosis or transferring genetic damages to subsequent generations. Finally, it shouldn't be carcinogenic as DNA alterations may promote a generation of malignant tumors ${ }^{6}$.

Previous studies have been made to evaluate biocompatibility of Zirconia Nanoparticles NP used in dentistry and there was a great debate regarding to what extent reinforcing NP will benefit or pose risks for human teeth ${ }^{7}$, some studies reported shortand long-term significant DNA damage in human cells inducing apoptosis associated with $\mathrm{ZrO}_{2}$ $\mathrm{NP}^{8}$, other studies have reported $\mathrm{ZrO}_{2} \mathrm{NP}$ could induce mild or no cytotoxic effects ${ }^{9}, 10$.Hence, experimental animal research was found to be a must to find out whether the addition of Zirconia NP to conventional veneering porcelain can negatively affect its biological properties or not.

\section{MATERIALS AND METHODS}

Twenty dogs were housed in the animal house "Faculty of Veterinary Medicine, Cairo University". Approval for this research was obtained from Research Ethics Committee, Faculty of Dentistry, Tanta University. The procedures were designed in accordance with the guidelines for the responsible use of animals in research as a part of scientific research esthetics recommendation of Research Ethics Committee, Faculty of Dentistry, Tanta University.

Dogs were randomly divided into four groups I, II, III and IV ( $\mathrm{n}=5)$ based on composition of veneering ceramic EX0, EX5, EX10 and EX20 respectively. Each group received general anesthesia, placed on surgical table, dogs' mouths were opened, and their mandibular teeth were cleaned and dried.

Primary impressions were taken for each dog using alginate for further preparation of custom trays. Mandibular 3rd premolar was prepared so that; a $1 \mathrm{~mm}$ occlusal reduction \& $1 \mathrm{~mm}$ shoulder finish line with a total convergence 6 degrees was made. Custom trays were loaded with siliconbased impression material" Zhermack Zetaplus Condensation silicon, Badia Polesine, Italy" to record impressions of prepared teeth, then poured using type IV extra-hard dental stone into master casts [Fig $1 \mathbf{a} \& \mathbf{1 b}]$.

Master casts were scanned "Smart optic", data was digitized where copings were designed with 
exocad software so that; axial walls thickness was $0.6 \mathrm{~mm}$ and occlusal thickness was $0.6 \mathrm{~mm}$. Zirconia blocks "katana ${ }^{T M}$ " were milled and post sintered at $1500^{\square} \mathrm{C}$ to produce zirconia copings. Experimental veneering ceramics (EX0 ,EX5, EX10 and EX20) were then manually layered over their corresponding zirconia cores, and underwent firing cycle at $930{ }^{\circ} \mathrm{C}$ for $45 \mathrm{~min}$ according to manufacturer's recommendations . Finished crowns were cemented to their corresponding prepared teeth using Panavia F 2.0 [Fig 1c].

After three months, Animals were again anesthetized and fixed on surgical and Two vertical incisions were made with a horizontal releasing incision extending from mesiobuccal to distobuccal line angles of $3^{\text {rd }}$ premolar to take gingival samples from all dogs and same procedures were repeated after 6 months to collect gingival samples. Gingival samples of all dogs at 3months and 6months underwent Real-time Polymerase chain reaction $[\boldsymbol{P C R}]$ to determine caspase-3 gene expression level (appoptic genes) compared to $\boldsymbol{G A P D H}$ the housekeeping gene (control genes) for assessment of possible genotoxicity of experimental .

Gene expression level values of both Caspase-3 and GAPDH were collected for all experimental groups (I, II, III and IV), tabulated. And underwent statistical analysis.

\section{RESULTS}

\section{Evaluation of Genotoxicity:}

Numerical casepase-3 gene expression level values for experimental groups I,II,III \& IV and for GAPDH (control group) after three and six months. One-way ANOVA and Tukey-test were used to compare difference between groups within the same period. Paired t- test was then used to compare gene expression levels at 3 and 6 months.

After 3months of crowns insertion in experimental animal mouths, GAPDH expression level recorded a mean value $0.96 \pm 0.01$ and reached 0.99 \pm 0.01 after 6months. A highly significant reduction in Caspase-3 gene expression level values was observed in all investigated groups compared to control GAPDH gene. On the other hand, Caspase 3 gene expression level showed highly significant increase in all experimental groups compared to each other as; group I was $(0.64 \pm 0.01) \&(0.648 \pm 0.016)$ after 3 and 6months respectively, Group II recorded $(0.67 \pm 0.02) \&(0.669 \pm 0.014)$, Group III recorded $(0.72 \pm 0.01) \&(0.733 \pm 0.015)$ and $(0.88 \pm 0.01) \&$ $(0.891 \pm 0.010)$ in Group IV [Fig.2].

Correlation analyses were performed to analyze the relation between Caspase-3 gene expression level at 3 and 6 months to identify the effect of time factor and the result was that there's no correlation exists.

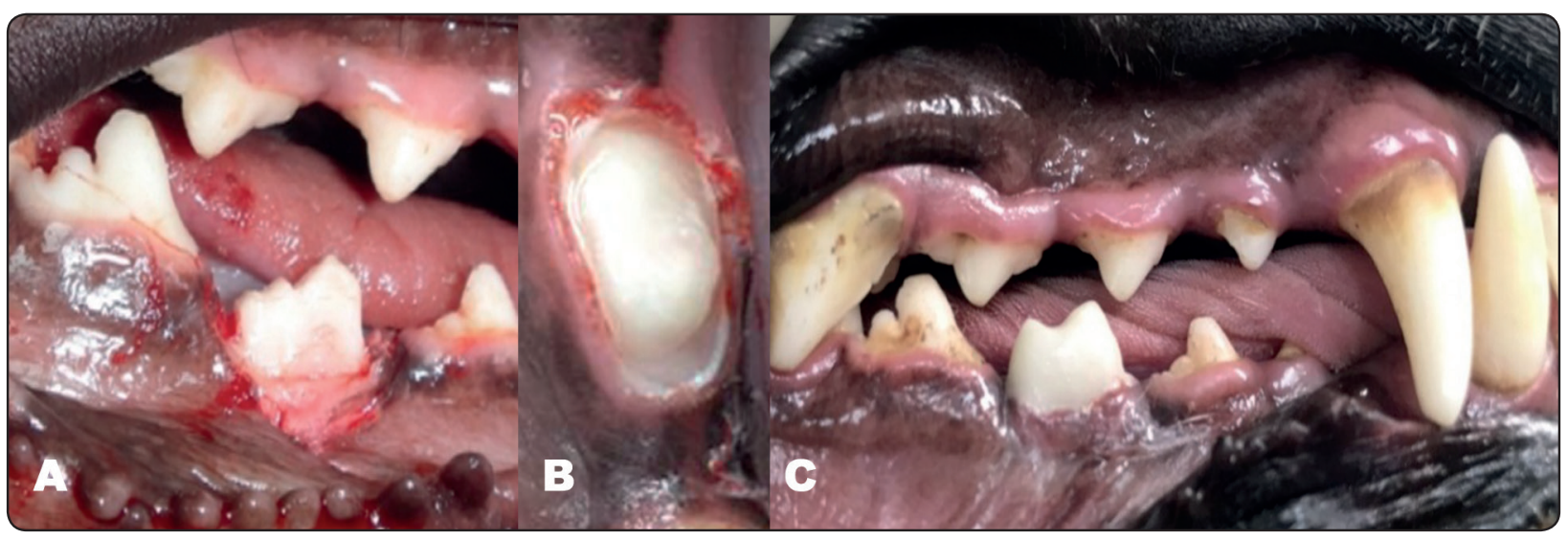

Fig 1. (a) $1.5 \mathrm{~mm}$ occlusal \& $1 \mathrm{~mm}$ axial reduction for mandibular $3 \mathrm{rd}$ premolar, (b) circumferential shoulder finish line and (c) cemented crown in place 


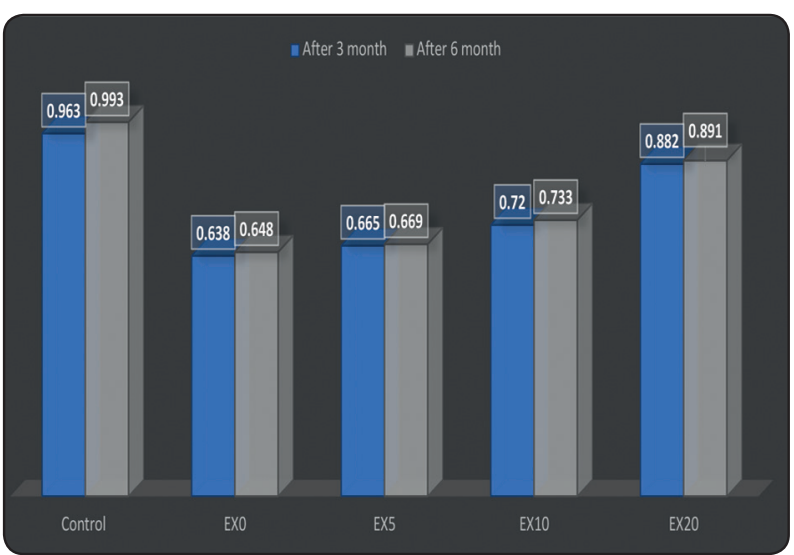

Fig. (2) Caspase-3 gene expression level values in experimental groups compared to control gene after 3 and 6 months.

\section{Evaluation of Local Biological Reactions}

Clinical evaluation of all experimental restorations showed absence of any signs of gingival inflammation around restorations during three and six months of the experiment except for some plaque retention. No signs of pulpal injury (hypersalivation, loss of appetite and bad breath) was detected. Surgical sites healed well. No allergic reaction provoked neither in the form of Lichenoid nor erosive lesions in oral mucosa or skin in experimental animals.

\section{DISCUSSION}

Experimental work was necessary in the current study to investigate biological effect of incorporating $\mathrm{ZrO}_{2}$ NPs into conventional veneering ceramic on local tissues [Gingival, pulpal \& mucosal] and on DNAs [Genotoxicity] of dogs ${ }^{11}$. Dog" was selected as an animal model because its teeth size is comparable to those of humans indicating an occlusal force near that of humans particularly; housed dogs due to their starch-rich diet. The selected tooth to be prepared was mandibular 3rd premolar not only due to its accessibility but also because of absence occlusal contacts at dog's premolars ${ }^{12}$.

After three and six months from restorations delivery, samples of gingival tissue close to experimental restorations were cut to undergo Realtime Polymerase Chain Reaction (PCR) test for assessment of genotoxicity. Real-time PCR was selected rather than conventional PCR as it's less time consuming, easier lab work \& more sensitive and precise ${ }^{13}$.

In this current study, the piece of tested DNA was Caspase3-Gene which plays vital role in regulating inflammatory responses and apoptosis when cells are threatened by noxious agents and therefore, it was selected to be screened in the present study ${ }^{14}$. On the other hand, Housekeeping genes e.g. GAPDH were used as control group as they're stable, normally expressed in cells and tissues and do not show changes under experimental or disease conditions ${ }^{15}$.

Results of the present study showed that after 3 months and 6 months, there was significant reduction in the expression level of caspase enzyme in all investigated groups compared to control gene. Decreased expression of apoptotic genes [Caspase-3 gene] constitute the potential mechanism of prolonged longevity [non-appoptic activity] an indicator for being non-genotoxic ${ }^{16}$ in accordance with Noushad et al., (2009) ${ }^{11}$ and Covacci et al.,(1999) ${ }^{17}$. on the contrary, the current study disagrees to Atalaya et al., (2018) ${ }^{18}$ and Brunner et al., (2006) ${ }^{19}$ who concluded that $\mathrm{ZrO}_{2}$ NPs can induce DNA damage and apoptosis at all studied concentrations. This different finding may due to the smaller particle size in Atalaya's ${ }^{18}$ and different shape and composition of NPs in Brunner's ${ }^{19}$ besides, the different assessment method.

Caspase 3 gene expression level showed highly significant increase in all experimental groups compared to Ex0 after 3months explained by presence of noxious agent in experimental samples, hence the initiator caspases were activated to stimulate Executioner Caspases [including Caspase 3; the gene under investigation] to start apoptosis as a defense response. On the other hand, after 6 months, an increase in the level of Caspase 3 gene 
expression was observed in all groups. The increased expression of appoptic genes proportionally with $\mathrm{ZrO}_{2} \mathrm{NP}$ concentration comes in accordance with Brunner et al., (2006) ${ }^{19}$, Atalaya et al., (2018) $)^{18}$ and Dhanalekshmi and Meena (2016) ${ }^{20}$ who accounted for DNA damage associated with $\mathrm{ZrO}_{2}$ nanoparticle due to their tiny size, greater surface area and high surface energy ${ }^{21}$ that enable them to intercalate within DNA strands resulting in DNA damage. Di Virgilio et al. ${ }^{22}$ added that the higher concentration of NPs, the more micronucleus frequency and DNA damage.

As for the Time Factor, the current study showed that gene expression level at the initial 3months was higher than that of 6months recall. This finding can be explained by the fact of ceramic ion leaching in saliva is always of higher rates, initially whereas, it reaches a constant rate after $<100$ days of exposure to the oral aqueous medium in accordance with Wataha and Lockwood (1998) ${ }^{23}$ and Elshahawy et al., (2013) ${ }^{24}$. Therefore, there's no correlation between 3- and 6-months gene expression level.

Regarding Clinical Findings, satisfactory soft tissue response was observed except for plaque retention on experimental crowns surface this may be due to lack of glaze firing cycle and resultant surface roughness.

\section{CONCLUSION}

- Experimental ceramics had no genotoxic effect.

- Appoptic gene expression recorded the highest level in Ex20, followed by Ex10, then Ex5 and finally Ex0.

- Satisfactory soft tissue response was observed for all experimental groups

\section{RECOMMENDATIONS}

Controlled clinical study should be carried out by applying experimental ceramics into a human volunteer over short period of time.

\section{REFERENCES}

1. Guazzato M, Albakry M, Ringer SP, Swain MV. Strength, fracture toughness and microstructure of a selection of allceramic materials Part II Zirconia-based dental ceramics. Dent Mater 2004; 20:449-456.

2. Wang H, Pallav P, Isgro G, Feilzer AJ. Fracture toughness comparison of three test methods with four dental porcelains. Dent Mater . 2007; 23:905-910.

3. Galusek D and Galusková. Alumina Matrix Composites with Non-Oxide Nanoparticle Addition and Enhanced Functionalities. Nanomaterials. 2015; 5: 115-143.

4. Palmero P. Review. Structural Ceramic Nanocomposites: A Review of Properties and Powders' Synthesis Methods. Nanomaterials. 2015; 5: 656-696.

5. Hoet PH, Bruske-Hohlfield I, Salata OV. Nanoparticles known and unknown health risks. J Nanobiotechnology. 2004; 2, 1:12.

6. Weiner M.L, Batt K.J, Putman D.L., Curren R.D, Yang L.L. Genotoxicity evaluation of lithium hypochlorite. Toxicology. 1996; 65:1-22.

7. Mädler L, Nel A, Nibg Li .Toxic Potential of Materials at the Nanolevel . Science. 2006; 311: 622-627.

8. Karunakaran G, Suriyaprabha R, Manivasakan P, Yuvakkumar R, Rajendran V, et al., Screening of in vitro cytotoxicity, antioxidant potential and bioactivity of nanoand micro-ZrO2 and - $\mathrm{TiO} 2$ particles. Ecotox Environ Safe. 2013; 93: 191-197.

9. Dalal A, Pawar V, McAllister K, Weaver C, Hallab NJ. Orthopedic implant cobalt-alloy particles produce greater toxicity and inflammatory cytokines than titanium alloy and zirconium alloy-based particles in vitro, in human osteoblasts, fibroblasts, and macrophages. J Biomed Mater Res A . 2012; 100: 2147-2158.

10. Gleiter H. Nanocrystalline materials. Progr. Mater. Sci. 1989; 33: 223-315

11. Noushad M, Kannan TP, Husein A, Abdullah H, Ismail AR. Genotoxicity evaluation of locally produced dental porcelain- an in vitro study using the Ames and Comet assays. Toxicol In Vitro. 2009 ; 23:1145-1150

12. Yang Y., Tang CA., Xia K. Study on crack curving and branching mechanism in quasi-brittle materials under dynamic biaxial loading. International Journal of Fracture. 2012; 177: 53-72. 
13. Wong M and Medrano J. Review. Real-time PCR for mRNA quantitation. BioTechniques. 2005; 39:75-85

14. Wang D, Hu J, Wang L, Hu Y, Tan F, Zhou H, Shao J, Yang W. The Apoptotic Function Analysis of p53, Apaf1, Caspase 3 and Caspase 7 during the Spermatogenesis of the Chinese Fire-Bellied Newt. PLoS ONE 2012; 7:1-20

15. Mazoochi T, Salehnia M, Pourbeiranvand M, Forouzandeh M, Mowla M et al., Analysis of apoptosis and expression of genes related to apoptosis in cultures of follicles derived from vitrified and non-vitrified ovaries.MHR.2009; 15: 155-164.

16. Greer S, Honeywell R, Geletu M, Arulanandam R, Raptis L. "Housekeeping genes; expression levels may change with density of cultured cells". Journal of Immunological Methods.2010; 355 (1-2): 76-79.

17. Covacci V, Bruzzese N, Maccauro G, Andreassi C, Ricci GA, et al. In vitro evaluation of the mutagenic and carcinogenic power of high purity zirconia ceramic. Biomaterials. 1999; 20:371-376.

18. Atalaya H, Çelikb A, Ayazc F. Investigation of genotoxic and apoptotic effects of zirconium oxide nanoparticles (20nm) on L929 mouse fibroblast cell line. ChemicoBiological Interactions. 2018; 296: 98-104
19. Brunner T.J., Wick P., Manser P. In vitro cytotoxicity of oxide nanoparticles: comparison to asbestos, silica, and the effect of particle solubility. Environ Sci Technol. 2006; 40:4374-4381.

20. Dhanalekshmi KI, Meena KS. DNA intercalation studies and antimicrobial activity of $\mathrm{AgZrO} 2$ core-shell nanoparticles in vitro. Mater. Sci. Eng. C.2016 ; 59 :1063-1068.

21. Rismanchian M, Khodaeian N, Bahramian L, Fathi M, Sadeghi-Aliabadi H. In-vitro Comparison of Cytotoxicity of Two Bioactive Glasses in Micropowder and Nanopowder forms. Iran J Pharm Res. 2013; 12: 437-443.

22. Di Virgilio AL, Arnal PM, Maisuls I. Biocompatibility of core/ shell particles: cytotoxicity and genotoxicity in human osteosarcoma cells of colloidal silica spheres coated with crystalline or amorphous zirconia, Mutat. Res. 2014;770:85-94.

23. Wataha JC, Nelson SK, Lockwood PE. Elemental release from dental casting alloys into biological media with and without protein. Dent Mater. 2001; 17:409-414.

24. Elshahawy W, Ajlouni R, James W, Abdellatif H, Watanabe I.Elemental ion release from fixed restorative materials into patient saliva. J. Oral Rehabil. 2013; 40:381-387. 